\title{
Validitas Konstruk Instrumen General Self Efficacy Scale Versi Indonesia
}

\author{
Riangga Novrianto, Anggia Kargenti Evanurul Marettih, Hasbi Wahyudi
}

\author{
Fakultas Psikologi UIN Sultan Syarif Kasim Riau \\ email:riangganovrianto@gmail.com
}

\begin{abstract}
Abstrak
Artikel INFO

Diterima:15 April 2019

Direvisi :13 Mei 2019

Disetujui: 17 Mei 2019

DOI:

http://dx.doi.org/10.24014/ jp.v14i2.6943

General Self-Efficacy Scale (GSES) merupakan instrumen pengukuran self efficacy yang menyeluruh dalam berbagai situasi yang dikembangkan oleh Schwarzer dan Jerusalem (1995). Penelitian ini bertujuan untuk menguji validitas konstruk instrumen General Self-Efficacy Scale (GSES) yang diadaptasi ke dalam Bahasa Indonesia. Subjek penelitian adalah mahasiswa UIN Sultan Syarif Kasim Riau dengan sampel 585 orang. Metode confirmatory factor analysis (CFA) digunakan untuk menguji konstruk instrumen ini dengan menggunakan software LISREL 8.80 (Jöreskog \& Sörbom, 2006). Hasil penelitian menunjukkan bahwa keseluruhan aitem General Self-Efficacy Scale (GSES) yang berjumlah 10 aitem bersifat unidimensional. Seluruh aitem General Self-Efficacy Scale (GSES) hanya mengukur satu faktor sehingga model satu faktor yang diteorikan dalam General Self-Efficacy Scale (GSES) dapat diterima.
\end{abstract}

Kata Kunci: Validitas Konstruk, General Self-Efficacy Scale, Confirmatory Factor Analysis.

\section{Construct Validity of Indonesian Version General Self Efficacy Scale}

\begin{abstract}
General Self-Efficacy Scale (GSES) is an instrument to measure generalized sense of self-efficacy in various situations which developed by Schwarzer and Jerusalem (1995). The aim of this research was to examine the construct validity of the General Self-Efficacy Scale (GSES). 585 students of UIN Sultan Syarif Kasim Riau participated in this research. Confirmatory Factor Analysis (CFA) was conducted to examine the construct validity of this instrument using LISREL 8.80 (Jöreskog \& Sörbom, 2006). Results indicated that all of ten-items of the General Self Efficacy (GSES) were unidimensional. All items of the General Self-Efficacy Scale (GSES) only measure one factor which confirmed the onefactor model assumed by the theory.
\end{abstract}

Keywords: Construct Validity, General Self-Efficacy Scale, Confirmatory Factor Analysis.

\section{Pendahuluan}

Self-efficacy didefinisikan sebagai keyakinan individu pada kemampuannya untuk melakukan tindakan yang dibutuhkan untuk memperoleh hasil yang diharapkan (Bandura, 1997). Self-efficacy berkaitan dengan pengendalian lingkungan yang menggambarkan individu dapat mengatasi berbagai tantangan dengan tindakan adaptif dan memperkuat individu untuk mengembangkan tujuan hidup yang lebih aktif (Rimm \& Jerusalem, 1999). Bandura (1997) juga mengemukakan bahwa self-efficacy mempengaruhi bagaimana individu berfikir, merasakan sesuatu, memotivasi dirinya, dan berperilaku. Self-efficacy telah banyak diteliti dalam berbagai bidang, mulai dari bidang pendidikan (Schunk, 1991; Chemers, $\mathrm{Hu}$, \& Garcia, 2001; Morton, Mergler, \& Boman, 2014), bidang industri dan organisasi 
(Akhtar, Ghayas, \& Adil, 2012), hingga bidang kesehatan (Buckley, 2014).

Bandura (1997) mengemukakan bahwa self-efficacy tersusun dari 3 dimensi, yaitu: (1) magnitude (tingkat kesulitan tugas yang dilakukan individu), (2) strength (keyakinan individu dengan kompetensinya dalam melakukan suatu tugas tertentu), (3) generality (luas bidang keyakinan individu dalam melakukan tugas tertentu). Self-efficacy umumnya dipahami sebagai konstruk mengacu pada tugas atau domain tertentu (Luszczynska, Gutiérrez-Doña, \& Schwarzer, 2005). Tetapi, beberapa ahli lainnya juga mengembangkan konsep selfefficacy yang menyeluruh yang merujuk pada keyakinan individu secara menyeluruh pada kemampuannya dalam mengatasi berbagai tuntutan atau situasi yang disebut dengan general self-efficacy (Sherer et al., 1982; Schwarzer \& Jerusalem, 1995). Hal ini diperkuat oleh pendapat Sherer et al., (1982) yang menjelaskan bahwa pengalaman keberhasilan dan kegagalan individu akan berpengaruh pada self-efficacy yang menyeluruh.

Meskipun Bandura (dalam Lönnfjord \& Hagquist, 2017) menentang konsep "skala serbaguna", ia mengakui bahwa self-efficacy dapat digeneralisasikan ketika terdapat persamaan yang terstruktur secara kognitif dalam berbagai kegiatan oleh individu. Contohnya adalah ketika terdapat berbagai macam tugas yang memerlukan kemampuan yang tidak jauh berbeda atau ketika kemampuan yang dibutuhkan untuk menyelesaikan berbagai aktivitas diperoleh secara bersamaan. Bandura (dalam Lönnfjord \& Hagquist, 2017) juga menjelaskan "transformasi pengalaman" yang dapat memperkuat keyakinan individu di bidang lainnya ketika kesuksesan diraih dalam bidang tertentu.

General self-efficacy berfokus pada keyakinan yang luas dan stabil pada kemampuan individu untuk dapat menghadapi berbagai situasi menekan secara efektif (Luszczynska, Gutiérrez-Doña, \& Schwarzer, 2005). General self-efficacy dapat menjelaskan cakupan yang lebih luas mengenai perilaku individu ketika konteksnya tidak terlalu spesifik. Scheier \& Carver (1992) juga mengemukakan bahwa pengukuran selfefficacy pada konteks umum cukup stabil dalam berbagai domain dan waktu pengukuran yang berbeda. Terdapat beberapa skala yang dikembangkan untuk mengukur general selfefficacy antara lain yang dikembangkan oleh Sherer et al., (1982) dan Schwarzer dan Jerusalem (1995).

General Self-Efficacy Scale pada mulanya dikembangkan oleh Matthias Jerusalem dan Ralf Schwarzer pada tahun 1979 yang terdiri dari 20 aitem (Scholz et al., 2002). Pada tahun 1995 instrumen ini dimodifikasi menjadi 10 aitem (Teo \& Kam, 2014). General Self-Efficacy Scale telah diterjemahkan ke dalam 32 bahasa dan dipergunakan dalam penelitian di berbagai negara. Scholz et al., (2002) mengemukakan bahwa instrumen ini memiliki konsistensi internal pada berbagai sampel di banyak negara dengan nilai Cronbach's alpha yang berkisar antara .75 hingga .91. Selain itu, dalam penelitian longitudinal juga ditemukan koefisien stabilitas (test re-test reliability) yang cukup baik berkisar antara .47 hingga .75 (Scholz et al., 2002).

Schwarzer etal., (1997) mengemukakan bahwa General Self-Efficacy Scale dirancang untuk dapat mengukur self-efficacy individu dalam cakupan yang luas, dan instrumen ini tidak dapat digunakan sebagai pengganti instrumen yang mengukur self-efficacy pada 
domain yang spesifik (contohnya, academic self-efficacy, teaching self-efficacy, dan work self-efficacy).

Schwarzer dan Jerusalem (1995) menjelaskan bahwa General Self-Efficacy Scale adalah instrumen yang bersifat unidimensional, atau hanya mengukur satu faktor yaitu general self-efficacy. Berbagai penelitian lain juga menemukan hasil yang mendukung unidimensionalitas dari General Self-Efficacy, diantaranya yaitu Crandall, Rahim, dan Yount (2015) yang menemukan bahwa General Self-Efficacy versi Qatar bersifat unidimensional. Selanjutnya, Rimm dan Jerusalem (1999) yang memperoleh hasil bahwa General Self-Efficacy versi Estonia memiliki karakteristik psikometri yang memuaskan dan dapat membedakan subkelompok dari sampel penelitian. Kemudian Lönnfjord dan Hagquist (2017) yang menemukan bahwa General Self-Efficacy Scale memiliki karakteristik psikometri yang baik dan menghasilkan hasil pengukuran yang konsisten. Tidak jauh berbeda, Sukmak, Sirisoonthon, dan Meena (2002) juga memperoleh hasil bahwa General SelfEfficacy Scale versi Thailand memiliki validitas dan reliabilitas yang baik serta bersifat unidimensional.

Schwarzer dan Jerusalem (1995) menjelaskan bahwa General Self-Efficacy Scale adalah instrumen yang bersifat unidimensional, atau hanya mengukur satu faktor yaitu general self-efficacy. Berbagai penelitian lain juga menemukan hasil yang mendukung unidimensionalitas dari General Self-Efficacy, diantaranya yaitu Crandall, Rahim, dan Yount (2015) yang menemukan bahwa General Self-Efficacy versi Qatar bersifat unidimensional.

Beberapapenelitian diatasmenunjukkan properti psikometri dan validitas dari General
Self-Efficacy Scale serta pentingnya pengujian validitas konstruk terhadap General Self-Efficacy Scale sebagai alat ukur yang bermanfaat dan banyak digunakan dalam penelitian di berbagai negara. Namun sejauh ini, belum ada penelitian yang menguji validitas konstruk dari aitem-aitem General Self-Efficacy Scale yang telah diadaptasi ke bahasa Indonesia. Oleh karena itu, pada penelitian ini peneliti akan menguji validitas konstruk General Self-Efficacy Scale yang telah diadaptasi ke bahasa Indonesia.

\section{Metode}

Partisipan

Sampel dalam penelitian ini adalah mahasiswa UIN Sultan Syarif Kasim Riau. Jumlah sampel adalah 585 orang, yang terdiri dari 179 orang laki-laki dan 406 perempuan. Pengambilan sampel dalam penelitian ini menggunakan teknik simple random sampling.

\section{Pengukuran}

Instrumen yang digunakan di dalam penelitian ini adalah adaptasi General SelfEfficacy Scale yang mengukur self-efficacy secara menyeluruh. Untuk menyesuaikan instrumen dengan karakteristik sampel penelitian, maka peneliti melakukan adaptasi. Adaptasi dilakukan baik secara bahasa dan jumlah pilihan jawaban.

Berdasarkan jumlah pilihan jawaban, General Self-Efficacy Scale terdiri dari 10 aitem dan menggunakan skala model Likert dengan empat pilihan jawaban, yaitu: "sangat tidak sesuai" hingga "sangat sesuai". Namun di dalam penelitian ini peneliti menggunkan opsi tengah (netral). Penggunaan opsi tengah dimaksudkan untuk memfasilitasi partisipan yang memiliki sikap moderat terhadap pernyataan yang diberikan (Klopfer \& Madden, 
1980). Tidak disediakannya opsi tengah dikhawatirkan akan menyebabkan partisipan merasa "dipaksa" untuk memilih pilihan jawaban secara bipolar. Pilihan jawaban yang disediakan terdiri dari lima pilihan jawaban, "sangat tidak sesuai", "tidak sesuai", "netral", "sesuai", dan "sangat sesuai".

Proses adaptasi dilakukan dengan menerjemahkan General Self-Efficacy Scale ke dalam bahasa Indonesia, selain itu peneliti juga menyesuaikan konteks bahasa maupun budaya dari instrumen yang digunakan. Peneliti kemudian memastikan aitem-aitem yang diterjemahkan tidak melenceng dari tujuan ukurnya. Setelah itu, peneliti melakukan proses back-translation (menerjemahkan kembali hasil terjemahan ke bahasa aslinya oleh pihak yang independen dan kompeten) yang dibantu oleh tenaga pengajar di Fakultas Psikologi UIN Sultan Syarif Kasim Riau yang merupakan native speaker dalam bahasa Inggris untuk memastikan tidak ada perubahan makna pada aitem-aitem yang diadaptasi.

Dalam penelitian ini validitas konstruk dari General Self-Efficacy Scale diuji dengan Confirmatory Factor Analysis (CFA) dengan bantuan software LISREL 8.80 (Jöreskog \& Sörbom, 2006). CFA adalah bagian dari analisis faktor yang digunakan untuk menguji sejauh mana masing-masing indikator merefleksikan dimensi dari sebuah konstruk (Pedhazur, 1997). Dalam hal ini, sejauh mana aitem-aitem dari sebuah instrumen penelitian valid dalam mengukur apa yang hendak diukur. CFA berbeda dengan EFA (Exploratory Factor Analysis) yang digunakan untuk mengetahui jumlah faktor yang hendak diukur dan menentukan pengelompokan aitem yang mengukur faktor tertentu. Di dalam CFA, peneliti membentuk model terlebih dahulu, menetapkan jumlah faktor (variabel laten) dan menentukan aitem-aitem (variabel teramati) yang mengukur faktor tertentu (Wijanto, 2008).

\section{Prosedur dan Analisis Data}

Adapun langkah-langkah untuk memperoleh aitem yang baik pada CFA adalah sebagai berikut (Umar, 2011):

1. Bahwa ada sebuah konsep atau trait yang didefinisikan secara operasional sehingga dapat disusun pertanyaan atau pernyataan untuk mengukurnya. Trait ini disebut faktor, sedangkan pengukuran terhadap faktor ini dilakukan melalui analisis terhadap respon atas aitemaitemnya.

2. Diteorikan setiap aitem hanya mengukur satu faktor saja, begitu pula sub-indikator hanya mengukur satu faktor juga, artinya setiap aitem maupun subtes bersifat unidimensional.

3. Dengan data yang tersedia dapat digunakan untuk mengestimasi matriks korelasi antar-aitem yang seharusnya diperoleh jika memang unidimensional. Matriks korelasi antar-aitem menurut $\mathrm{H}_{0}$ disebut sigma $(\Sigma)$, kemudian dibandingkan dengan matriks dari data empiris yang disebut matriks (S). Jika teori tersebut itu benar (unidimensional) maka tentunya tidak ada perbedaan antara matriks $\Sigma$ dengan matriks $S$ atau dapat juga dinyatakan sebagai $\Sigma$ - $S=0$.

4. Pernyataan tersebut dijadikan hipotesis nihil yang kemudian diuji dengan chisquare. Jika chi-square tidak signifikan $p$ $>.05$ maka hipotesis nihil tersebut "tidak ditolak". Artinya teori unidimensionalitas tersebut dapat diterima bahwa aitem ataupun subtes instrumen hanya mengukur satu faktor saja.

5. Adapun dalam memodifikasi model 
pengukuran dilakukan dengan cara membebaskan parameter berupa korelasi kesalahan pengukuran. Hal ini terjadi ketika suatu aitem mengukur selain faktor yang hendak diukur. Setelah beberapa kesalahan pengukuran dibebaskan untuk saling berkorelasi, maka akan diperoleh model yang fit, maka model terakhir inilah yang akan digunakan pada langkah selanjutnya.

6. Jika model fit, maka langkah selanjutnya adalah melihat apakah aitem signifikan atau tidak mengukur apa yang hendak diukur dengan menggunakan $t$-value. Jika hasil $t$-value tidak signifikan $(t<$ 1.96) maka aitem tersebut tidak signifikan dalam mengukur apa yang hendak diukur dan harus dieliminasi.

7. Selanjutnya, melihat arah dari koefisien muatan faktor (factor loading). Jika suatu aitem memiliki muatan faktor negatif, maka aitem tersebut harus dieliminasi karena tidak sesuai dengan pengukuran.

8. Sebagai kriteria tambahan, dapat dilihat pula banyaknya korelasi parsial antar kesalahan pengukuran, yaitu kesalahan pengukuran pada suatu aitem yang berkorelasi dengan kesalahan pengukuran pada aitem lainnya. Jika pada suatu aitem terdapat terlalu banyak korelasi seperti ini (misalnya lebih dari tiga), maka aitem tersebut juga akan dieliminasi. Alasannya adalah karena aitem yang demikian mengukur hal lain selain apa yang hendak diukur.

\section{Hasil}

Pada General Self-Efficacy Scale terdapat 10 aitem. Peneliti telah melakukan uji validitas konstruk pada instrumen ini dengan menguji apakah 10 aitem yang ada bersifat unidimensional, artinya hanya mengukur konstruk self-efficacy. Hasil CFA yang dilakukan dengan model satu faktor diperoleh model tidak fit dengan chi-square $=264.74$, $\mathrm{df}=35, p$-value $=0.00000$, RMSEA $=0.106$ (lihat Gambar 1).

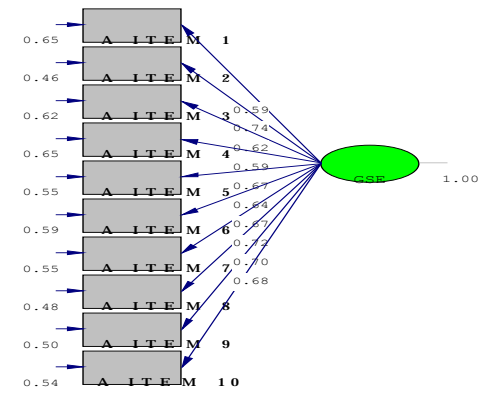

Gambar 1. Path Diagram CFA Sebelum Modifikasi Model

Untuk itu peneliti melakukan modifikasi terhadapmodeldimanakesalahan pengukuran pada beberapa aitem diperbolehkan berkorelasi dengan kesalahan pengukuran pada aitem lainnya. Maka diperoleh model fit dengan chi-square $=34.87, \mathrm{df}=26, p$-value $=0.11444$, RMSEA $=0.024$. Karena $p$-value telah menghasilkan nilai $p>.05$ ( tidak signifikan) maka dinyatakan bahwa models satu faktor (unidimensional) dapat diterima, bahwa seluruh aitem hanya mengukur satu faktor saja yaitu self-efficacy (lihat Gambar 2).

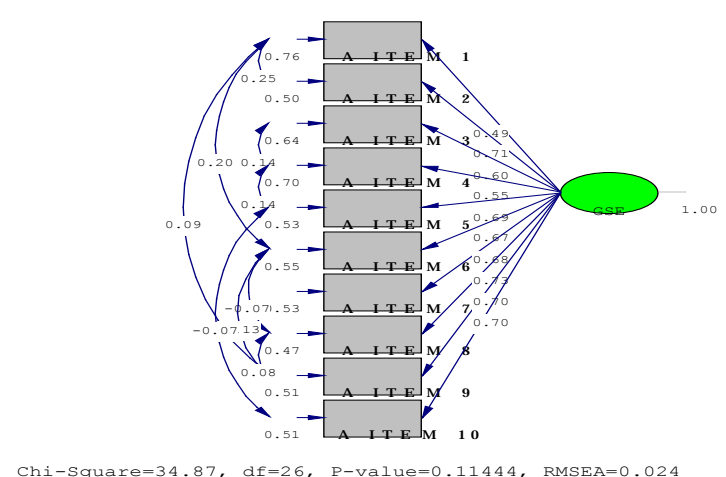

Gambar 2. Path Diagram CFA Setelah Modifikasi Model

Selanjutnya peneliti melihat signifikan atau tidaknya aitem-aitem instrumen dalam mengukur faktor yang hendak diukur sekaligus untuk menentukan apakah aitem tersebut 
perlu dieliminasi atau tidak. Dalam hal ini yang diuji adalah hipotesis nihil tentang koefisien muatan faktor dari masing-masing aitem. Pengujiannya dilakukan dengan melihat $t$-value pada setiap koefisien muatan faktor, dengan kriteria $t>1.96$. Pada Tabel 1 dapat diketahui bahwa seluruh aitem signifikan $(t>$ 1.96).

Tabel 1. Muatan Faktor Aitem General SelfEfficacy Scale Setelah Model Fit

\begin{tabular}{ccccc}
\hline $\begin{array}{c}\text { Nomor } \\
\text { aitem }\end{array}$ & Koefisien & $\begin{array}{c}\text { Standar } \\
\text { eror }\end{array}$ & t-value & Sig. \\
\hline AITEM 1 & .49 & .04 & 11.83 & $\mathrm{~V}$ \\
AITEM 2 & .71 & .04 & 18.71 & $\mathrm{~V}$ \\
AITEM 3 & .60 & .04 & 15.16 & $\mathrm{~V}$ \\
AITEM 4 & .55 & .04 & 13.55 & $\mathrm{~V}$ \\
AITEM 5 & .69 & .04 & 17.84 & $\mathrm{~V}$ \\
AITEM 6 & .67 & .04 & 17.12 & $\mathrm{~V}$ \\
AITEM 7 & .68 & .04 & 18.00 & $\mathrm{~V}$ \\
AITEM 8 & .73 & .04 & 18.95 & $\mathrm{~V}$ \\
AITEM 9 & .70 & .04 & 18.14 & $\mathrm{~V}$ \\
AITEM 10 & .70 & .04 & 18.37 & $\mathrm{~V}$ \\
\hline
\end{tabular}

Keterangan: $\mathrm{V}=$ signifikan $(t>1.96) ; \mathrm{X}=$ tidak signifikan

Selanjutnya melihat muatan faktor dari aitem apakah ada yang bermuatan faktor negatif. Berdasarkan Tabel 1 diketahui bahwa seluruh aitem bermuatan faktor positif, sehingga tidak ada aitem yang harus dieliminasi karena bermuatan faktor negatif.

Pada model pengukuran ini juga terdapat kesalahan pengukuran aitem yang saling berkorelasi. Secara keseluruhan terdapat 9 korelasi kesalahan pengukuran. Aitem-aitem dengan kesalahan pengukuran yang paling banyak berkorelasi dengan kesalahan pengukuran lainnya adalah aitem nomor 1 , nomor 6 , dan nomor 9 dengan korelasi parsial masing-masing sebanyak 3 kali. Oleh karena korelasi parsial antara kesalahan pengukuran aitem tidak terlalu banyak (tidak lebih dari 3 kali) maka tidak ada aitem yang harus dieliminasi.

\section{Pembahasan}

Hasil uji validitas konstruk pada General Self-Efficacy Scale menunjukkan bahwa aitem-aitem instrumen ini secara signifikan bersifat unidimensional, yaitu benar hanya mengukur konstruk self-efficacy secara menyeluruh. Artinya tidak terdapat perbedaan antara data yang diperoleh dengan teori.

Hasil ini didukung oleh temuan yang diperoleh oleh peneliti-peneliti sebelumnya (Schwarzer et al., 1997; Rimm \& Jerusalem, 1999; Scholz et al., 2002; Luszczynska, Gutiérrez-Doña, \& Schwarzer, 2005; Scherbaum, Cohen-Charash, \& Kern, 2006; Löve, Moore, \& Hensing, 2011) yang menemukan bahwa General Self-Efficacy bersifat unidimensional, valid dan reliabel pada berbagai populasi penelitian dan pada budaya yang berbeda. Hanya saja model satu faktor yang diajukan pada awalnya tidak langsung fit dan menunjukkan $p$-value yang signifikan $(p<$ .05) sehingga memperlukan modifikasi model di mana kesalahan pengukuran pada setiap aitem diperbolehkan untuk berkorelasi.

Secara keseluruhan tidak terdapat muatan faktor negatif pada setiap aitem, sehingga tidak ada aitem yang perlu dieliminasi karena bermuatan faktor negatif. Demikian pula setelah ditinjau berdasarkan $t$-value, seluruh aitem valid dan tidak ada aitem yang perlu dieliminasi karena memiliki t-value < 1.96. Akan tetapi yang perlu menjadi catatan adalah terdapat beberapa aitem yang memiliki korelasi parsial antar kesalahan pengukuran yang cukup banyak yaitu pada aitem nomor 1, 6, dan 9 dengan masing-masing korelasi parsial sebanyak 3 kali. Mendekati ambang batas korelasi parsial yang mengharuskan untuk mengeliminasi aitem (korelasi parsial diatas 3), sehingga perlu dipertimbangkan untuk penggunaan di dalam pengukuran.

Didalam penelitian ini terdapat beberapa 
keterbatasan, diantaranya adalah proses adaptasi instrumen yang belum melaksanakan sepenuhnya tahapan-tahapan dalam proses adaptasi lintas-budaya instrumen. Panduan adaptasi lintas-budaya instrumen yang sering dirujuk seperti "Guidelines for the Process of Cross-Cultural Adaptation of Self-Report Measures" (Beaton, Bombardier, Guillemin, \& Ferraz, 2000). Di dalam panduan adaptasi instrumenyang dikemukakanolehBeatonetal., (2000) terdapat lima tahapan adaptasi lintasbudaya instrumen yang salah satu tahapnya adalah expert comittee (pemeriksaan aitemaitem instrumen sebelum oleh beberapa ahli sebelum dilakukan uji-coba).

Di dalam penelitian ini peneliti hanya melakukan adaptasi bahasa dan konteks serta back-translation (menerjemahkan kembali hasil terjemahan ke bahasa aslinya oleh pihak yang independen dan kompeten). Diharapkan pada peneliti selanjutnya untuk dapat melaksanakan secara keseluruhan tahapan adaptasilintas-budaya instrumen agar diperoleh aitem-aitem yang berkualitas baik. Selain itu, penelitian ini juga masih terbatas pada sampel mahasiswa. Perluasan variasi sampel dapat dipertimbangkan agar dapat mengetahui bagaimana validitas konstruk instrumen pada sampel yang berbeda.

\section{Kesimpulan}

Uji validitas konstruk pada General SelfEfficacy Scale menunjukkan bahwa aitemaitem instrumen ini bersifat unidimensional yang hanya mengukur satu faktor yaitu selfefficacy dan mendukung model satu faktor yang diteorikan. Aitem-aitem instrumen ini seluruhnya memiliki $t$-value $>1.96$ dan bermuatan faktor positif. Sehingga GeneralSelf Efficacy Scale terbukti valid dalam mengukur konstruk self-efficacy dalam konteks yang menyeluruh.

Instrumen ini dapat digunakan sebagai instrumen yang valid dalam mengukur selfefficacy secara menyeluruh pada mahasiswa. Instrumen ini juga dapat digunakan sebagai instrumen penelitian bagi para peneliti dan mahasiswa yang tertarik untuk meneliti variabel self-efficacy dalam berbagai bidang seperti pendidikan, klinis, industri dan organisasi yang tidak mengacu pada domain yang spesifik. Selain itu, instrumen ini juga diharapkan dapat digunakan bagi peneliti selanjutnya yang ingin meneliti self-efficacy secara menyeluruh pada subjek penelitian lain, seperti siswa, karyawan, atau pada populasi khusus lainnya.

Peneliti selanjutnya diharapkan dapat menguji validitas instrumen ini dengan menggunakan teknik lainnya, misalnya dengan validitas konvergen, validitas diskriminan, maupun dengan metode multitrait-multimethod (MTMM).

\section{Daftar Pustaka}

Akhtar, S., Ghayas, S., \& Adil, A. (2012). SelfEfficacy and Optimism as Predictors of Organizational Commitment among Bank Employees. International Journal of Research Studies in Psychology, 5(1). 1-10.

Bandura,A. (1997). Self-Efficacy: The Exercise of Control. New York: Freeman.

Beaton, D. E., Bombardier, C., Guillemin, F., \& Ferraz, M. B. (2000). Guidelines for the Process of Cross-Cultural Adaptation of Self-Report Measures. SPINE, 25(4). 3186-3191.

Buckley, J. (2014). Exercise Self-Efficacy Intervention in Overweight and Obese Women. Journal of Health Psychology, 19(1). 1-11.

Chemers, M. M., Hu, L., Garcia, B. F. (2001). Academic Self-Efficacy and First-Year College Adjustment Performance and Adjustment. Journal of Educational Psychology, 93(1). 55-64.

Crandall, A., Rahim, H. F. A., \& Yount, K. M. (2015). Validation of the General SelfEfficacy Scale among Qatari Young Women. Eastern Mediterranean Health Journal, 21(12). 891-896.

Jöreskog, K. \& Sörbom, D. (2006). LISREL 
8.80 for Windows. Computer Software. Scientific Software International, Inc.

Klopfer, F. J., \& Madden, T. M. (1980). The Middlemost Choice on Attitude Items. Personality and Social Psychology Bulletin, 6(1), 97-101.

Lönnfjord, V. \& Hagquist, C. (2017). The Psychometric Properties of the Swedish Version of the General Self-Efficacy Scale; A Rasch Analysis Based on Adolescent Data. Current Psychology, 36(1). 1-13.

Löve, J., Moore, C. D., \& Hensing, G. (2011). Validation of the Swedish Translation of the General Self-Efficacy Scale. Quality of Life Research, 21(7). 1249-1253.

Luszczynska, A. Gutiérrez-Doña, B., \& Schwarzer, R. (2005). General SelfEfficacy in Various Domains of Human Functioning; Evidence from Five Countries. International Journal of Psychology, 40(2). 80-89.

Morton, S., Mergler, A., \& Boman, P. (2014). Managing the Transition: The Role of Optimism and Self-Efficacy for FirstYear Australian University Students. Australian Journal of Guidance and Counselling, 24(1). 90-108.

Pedhazur, E. J. (1997). Multiple Regression in Behavioral Research: Explanation and Prediction (3rd Edition). New York: Thomson Learning, Inc.

Rimm, H., \& Jerusalem, M. (1999). Adaptation and Validation of an Estonian Version of the General Self-Efficacy Scale (ESES). Anxiety, Stress, \& Coping: An International Journal, 12(3). 329-345.

Scheier, M. F. \& Carver, C. S. (1992). Effects of Optimism on Psychological and Physical Well-Being; Theoretical Overview and Empirical Update. Cognitive Therapy and Research, 16(2). 201-228.

Scherbaum, C. A., \& Cohen-Charash, Y., \& Kern, M. J. (2006). Measuring General Self-Efficacy, A Comparison of Three Measures Using Item Response Theory. Educational and Psychological Measurement, 66(6). 1047-1063.

ScholzU. etal., (2002). Is General Self-Efficacy a Universal Construct? Psychometric Findings from 25 Countries. European Journal of Psychological Assessment, 18(3). 242-251.

Schunk, D. H. (1991). Self-Efficacy and Academic Motivation. Educational Psychologist, 26(3). 207-231.

Schwarzer, R. \& Jerusalem, M. (1995).
Generalized Self-Efficacy Scale. Dalam Measures in Health Psychology A User's Portofolio, Causal and Control Beliefs (pp. 35-37). Windsor: NFER-NELSON.

Schwarzer, R., et al., (1997). The Assessment of Optimistic Self-Beliefs; Comparison of the German, Spanish,and Chinese Versions of the General Self-Efficacy Scale. Applied Psychology: An International Review, 46(1). 69-88.

Sherer, M. et al., (1982). The Self-Efficacy Scale: Construction and Validation. Psychological Reports, 51(2). 663-671.

Sukmak, V., Sirisoonthon, A., \& Meena, P. (2002). Validity of The General Perceived Self-Efficacy Scale. Journal of Psychiatric Association of Thailand, 47(1). 31-37.

Teo, T. \& Kam, C. (2014). A Measurement Invariance Analysis of the General Self-Efficacy Scale on Two Different Cultures. Journal of Psychoeducational Assessment, 32(8). 762-767.

Umar, J. (2011). Analisis Faktor Konfirmatorik. Manuskrip Tidak Dipublikasikan. Fakultas Psikologi, UIN Syarif Hidayatullah Jakarta.

Wijanto, S. H. (2008). Structure Equation Modeling dengan LISREL 8.8: Konsep \& Tutorial. Yogyakarta: Graha IImu. 


\section{Lampiran \\ Adaptasi Bahasa Indonesia General Self-Efficacy Scale}

Keterangan alternatif jawaban:

STS (Sangat Tidak Sesuai), TS (Tidak Sesuai), N (Netral), CS (Cukup Sesuai), SS (Sangat Sesuai)

Contoh pengerjaan:

\begin{tabular}{|c|l|c|c|c|c|c|}
\hline NO & PERNYATAAN & STS & TS & N & CS & SS \\
\hline 1. & $\begin{array}{l}\text { Saya dapat selalu menyelesaikan masalah yang sulit jika } \\
\text { saya berusaha keras }\end{array}$ & & & & & $\checkmark$ \\
\hline
\end{tabular}

Keterangan: Artinya Anda merasa sangat sesuai dengan pernyataan di atas.

\begin{tabular}{|c|c|c|c|c|c|c|}
\hline No. & Pernyataan & STS & TS & $\mathbf{N}$ & CS & SS \\
\hline 1 & $\begin{array}{l}\text { Saya dapat selalu menyelesaikan masalah yang } \\
\text { sulit jika saya berusaha keras. }\end{array}$ & & & & & \\
\hline 2 & $\begin{array}{l}\text { Saya mampu mencari cara untuk menyelesaikan } \\
\text { masalah jika ada sesuatu yang menghambat } \\
\text { tujuan saya. }\end{array}$ & & & & & \\
\hline 3 & $\begin{array}{l}\text { Mudah bagi saya untuk tetap pada tujuan dan } \\
\text { mencapai tujuan saya }\end{array}$ & & & & & \\
\hline 4 & $\begin{array}{l}\text { Saya yakin bahwa saya dapat bertindak dengan } \\
\text { baik dalam situasi yang tidak terduga }\end{array}$ & & & & & \\
\hline 5 & $\begin{array}{l}\text { Berkat kemampuan saya, saya tahu bagaimana } \\
\text { cara menghadapi situasi yang tidak terduga }\end{array}$ & & & & & \\
\hline 6 & $\begin{array}{l}\text { Saya dapat menyelesaikan berbagai permasalahan } \\
\text { jika saya sungguh-sungguh dalam melakukannya }\end{array}$ & & & & & \\
\hline 7 & $\begin{array}{l}\text { Saya dapat tetap tenang saat menghadapi } \\
\text { kesulitan karena saya dapat mengandalkan } \\
\text { kemampuan saya untuk mengatasi hal tersebut }\end{array}$ & & & & & \\
\hline 8 & $\begin{array}{l}\text { Saat berhadapan dengan sebuah masalah, saya } \\
\text { mempunyai banyak ide untuk mengatasinya }\end{array}$ & & & & & \\
\hline 9 & $\begin{array}{l}\text { Ketika berada dalam situasi sulit, saya dapat } \\
\text { memikirkan cara untuk keluar dari kesulitan } \\
\text { tersebut }\end{array}$ & & & & & \\
\hline 10 & $\begin{array}{l}\text { Apapun yang terjadi, saya akan dapat } \\
\text { mengatasinya dengan baik }\end{array}$ & & & & & \\
\hline
\end{tabular}

